\title{
Comparative Analysis of Main Clinical Features and Survival in Patients with Cutaneous Malignant Melanoma with and without Sentinel Lymph Node Biopsy
}

\section{Strashilov Strahil ( $\nabla$ dr.strashilov@gmail.com )}

Meditsinski universitet - Pleven https://orcid.org/0000-0002-4104-948X

Joana Ivanova Simeonova

Medical University-Sofia: Medicinski universitet-Sofia

Assia Andrianova Konsoulova

Complex Oncological Center Burgas

Mariela Borisova Vasileva-Slaveva

Tyrolean Cancer Research Institute

Angel Dancev Yordanov

Medical University - Pleven: Meditsinski universitet - Pleven

\section{Research}

Keywords: Sentinel lymph node biopsy, Malignant melanoma of skin, Melanoma

Posted Date: October 9th, 2020

DOI: https://doi.org/10.21203/rs.3.rs-88876/v1

License: (c) (1) This work is licensed under a Creative Commons Attribution 4.0 International License.

Read Full License 


\section{Abstract}

Background Sentinel lymph node biopsy is fundamental in the treatment and prognosis of cutaneous malignant melanoma. The aim of this study is to identify differences in baseline clinical characteristics and survival of patients with melanoma with and without sentinel lymph node biopsy (SLNB) performed.

Methods In 2018, a retrospective study of 151 patients with malignant melanoma (MM) was conducted. The patients were hospitalized at the Second Clinic of University Hospital - Pleven, for the period 2012 to 2017. The patients were divided into two groups: Group A included 58 (38.4\%) patients with SLNB performed; Group B included 93 (61.6\%) patients who did not undergo SLNB. A double-detection method was used while performing SLNB.

Results The incidence of achromatic malignant melanoma is significantly higher in patients without SLNB performed (12 or $12.9 \%$ ), than in patients with SLNB performed $(2$ or $3.4 \%)-\chi 2=3.796, d f=1, p=$ 0.051 . Of all 151 patients in the study, 46 died, representing 30.5 per 100 patients with melanoma. Mortality rate is higher in patients without SLNB (32.3\% versus $27.6 \%$ in Group A). However, the differences in the two groups are not statistically significant.

Conclusions Patients with achromatic melanoma have significantly fewer SLN biopsies performed because of a late diagnosis. Most of our patients are diagnosed at a later stage when lymphatic metastases are already present which leads to a significant increase in lymph node dissections performed. There is no significant difference in mortality and survival in the SLNB and non-SLNB groups.

\section{Background}

The term melanoma was first employed by René Laennec, who in his manuscript in 1812 describes a case of disseminated disease [1]. Cutaneous malignant melanoma develops after malignant transformation of its pigment-forming melanocytes [2] Australia and New Zealand are world leaders in terms of morbidity and mortality rates of 54/100,000 and 5.6/100,000, respectively, for 2015 [3]. In Bulgaria, morbidity rate for the same year is $6.5 / 100,000$, and the mortality rate is $2.1 / 100,000$. The main risk factors for its development are: exposure to ultraviolet radiation [4], skin phototype [5], presence of pigmented nevi [6], severe sunburn [7], and geographical location [8].

Sentinel lymph node biopsy is fundamental in the treatment and prognosis of cutaneous malignant melanoma. Sentinel lymph node is defined as the first stop for metastases accumulation from a malignant tumor process. Depending on the detection method used, the first sentinel lymph node detected is described as a hot node (radiocolloid labelled), or blue stained (Patent Blue V marked) [9]. Its histological examination provides an accurate prognosis of the involvement of other nodes in the lymphatic chain. During SLN biopsy the sentinel ymph node(s) is surgically removed. Patients with a histologically positive for metastases sentinel lymph node undergo compulsory complete lymph node dissection of the entire basin. 
Sentinel lymph node biopsy in the management of cutaneous malignant melanoma was first performed by Donald Morthon and team in 1992, in order to avoid the frequent postoperative complications occurring with the previously used elective lymph node dissection $[10,11]$.

The aim of this study is to identify differences in baseline clinical characteristics and survival rates of two groups of patients with cutaneous malignant melanoma - with and without sentinel lymph node biopsy (SLNB) performed.

\section{Methods}

In 2018, a retrospective study of 151 patients with malignant melanoma (MM) was conducted. The patients were hospitalized at the Second Clinic of University Hospital - Pleven, for the period 2012 to 2017. Patients with a diagnosis other than MM were excluded from the study.

The patients were divided into two groups: Group A included 58 (38.4\%) patients with SLNB performed; Group B included 93 (61.6\%) patients who did not undergo SLNB (Table 1). A double-detection method was used while performing SLNB with the application of Technetium Tc-99m Sulfur Colloid radiopharmaceutical and Patent Blue $V$ staining dye.

The documentary method is used to extract primary sociological information. Data is collected on: age, sex, Breslow thickness, level of tumour invasion (Clark level), histologic variant, lymph node dissection performed, stage of disease (TNM classification), and survival (expressed in months).

The statistical software used for data processing is SPSS v.24.0. Descriptive statistics are applied. Pearson's chi-squared test $(\chi 2)$ is used to identify differences in the groups, and Spearman's Rank correlation coefficient is used to measure correlation dependencies. Statistically significant are considered the results at a $p$-value significance level $(p)$ less than or equal to 0.05 . Survival estimates for both groups of patients with MM are computed by log rank test and Kaplan-Meier survival curve.

\section{Results}

\section{Demographic characteristics}

Table 1 shows the distribution of patients in the two groups - total, by age and sex.

Table 1. Distribution of patients with MM according to SLNB performance - total, by sex and age (Valid N, \%) 


\begin{tabular}{|l|l|l|l|}
\hline Variable & $\begin{array}{l}\text { Group 0 } \\
\text { Number (\%) }\end{array}$ & $\begin{array}{l}\text { Group B } \\
\text { Number (\%) }\end{array}$ & $\begin{array}{l}\text { Total } \\
\text { Number (\%) }\end{array}$ \\
\hline Gender & $26(44.8 \%)$ & $52(55.9 \%)$ & $78(51.7 \%)$ \\
Male & $32(55.2 \%)$ & $41(44.1 \%)$ & $73(48.3 \%)$ \\
Female & $58(100.0 \%)$ & $93(100.0 \%)$ & $151(100.0 \%)$ \\
Total & & & \\
\hline Age & $63.5(17 \div 81)$ & $67.0(32 \div 91)$ & $65.0(17 \div 91)$ \\
Mean age (Mdn, Min $\div$ Max) & $\mathbf{5 8 ( 3 8 . 4 \% )}$ & $\mathbf{9 3 ( 6 1 . 6 \% )}$ & $\mathbf{1 5 1 ( 1 0 0 . 0 \% )}$ \\
\hline Total & \multicolumn{2}{|l}{} &
\end{tabular}

The mean age of patients with MM is 65.0 years, with the youngest being 17 years of age and the oldest being 91 years. The median age in Group B is 67.0 years and is higher than in Group A - 63.5 years.

The distribution of patients by sex indicates 78 (51.7\%) males (44.8\% in Group A, and $55.9 \%$ in Group B, respectively).

\section{Clinical characteristics}

\subsection{Histological variant of the tumor}

The incidence of achromatic malignant melanoma (Fig. 1) is significantly higher in patients without SLNB performed ( 12 or $12.9 \%$ ), than in patients with SLNB performed $(2$ or $3.4 \%)-\chi 2=3.796, d f=1, p=$ 0.051 . There is a weak correlation $(r=0.159, p=0.050, N=151)$.

\subsection{Melanoma thickness (Breslow classification)}

The mean melanoma thickness is $2.50 \mathrm{~mm}$ (Mdn, $0 \div 11 \mathrm{Min}$, Max) in patients in Group $\mathrm{B}$, and is higher than in patients in Group A (1.8 Mdn, $1 \div 5$ Min, Max).

Using Breslow classification, we report that the proportion of patients with melanoma thickness greater than $4.1 \mathrm{~mm}$ in Group B (32.2\%) is approx. three times higher compared to Group A (13.8\%). Differences are significant $(X 2=29.563, d f=5, p=0.001)$. For the rest of the cases, there is a higher proportion of patients with MM and performed SLNB, with tumor invasion in the range of $0.76-1.0 \mathrm{~mm}, 1.1-2.0 \mathrm{~mm}$ and $2.1-4.0 \mathrm{~mm}$ (Table 2). There is no correlation between the two variables $(p=0.547)$.

\subsection{Performed lymph node dissection}

Lymph node dissection was performed in 48 (31.8\%) of patients with MM, respectively in $18(31.0 \%)$ of patients in Group A and 30 (32.3\%) of patients in Group B (Table 2). Causes for lymph node dissection were different in two comparative groups. The cause in non-SLNB patients was the discovery of a 
clinically positive lymph node, whereas in SLNB patients the cause was a positive sentinel lymph node identified by histological analysis. There were no statistically significant differences between the groups studied.

Table 2. Distribution of the patients in Group $\square$ and Group B by Breslow`s thickness of MM, TNM Classification and lymph node dissection (Number, \%)

\begin{tabular}{|c|c|c|c|}
\hline Variable & $\begin{array}{l}\text { Group } \mathrm{P} \\
\text { Number (\%) }\end{array}$ & $\begin{array}{l}\text { Group B } \\
\text { Number (\%) }\end{array}$ & $\begin{array}{l}\text { Total } \\
\text { Number (\%) }\end{array}$ \\
\hline \multicolumn{4}{|l|}{ Breslow`s thickness of MM } \\
\hline In situ & $0(0.0 \%)$ & $10(10.8 \%)$ & $10(6.6 \%)$ \\
\hline Thickness less than 0.75 & $4(6.9 \%)$ & $15(16.1 \%)$ & $19(12.6 \%)$ \\
\hline Thickness $0.76 \div 1.0$ 마 & $5(8.6 \%)$ & $5(5.4 \%)$ & $10(6.6 \%)$ \\
\hline Thickness $1.1 \div 2.0$ & $29(39.7 \%)$ & $9(9.7 \%)$ & $32(21.2 \%)$ \\
\hline 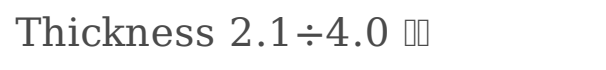 & $18(31.0 \%)$ & $24(25.8 \%)$ & $42(27.8 \%)$ \\
\hline Thickness greater than $4.0 \mathrm{~B}$ & $8(13.8 \%)$ & $30(32.2 \%)$ & $38(35.2 \%)$ \\
\hline Total & $58(100.0 \%)$ & $93(100.0 \%)$ & $151(100.0 \%)$ \\
\hline \multicolumn{4}{|l|}{ TNM Classification } \\
\hline Stage 0 & $1(1.7 \%)$ & $8(8.6 \%)$ & $9(6.0 \%)$ \\
\hline Stage IA & $4(6.9 \%)$ & $17(18.1 \%)$ & $21(13.9 \%)$ \\
\hline Stage IB & $17(29.3 \%)$ & $9(9.7 \%)$ & $26(17.2 \%)$ \\
\hline Stage IIA & $8(13.8 \%)$ & $5(5.4 \%)$ & $13(8.6 \%)$ \\
\hline Stage IIB & $7(12.1 \%)$ & $6(6.5 \%)$ & $13(8.6 \%)$ \\
\hline Stage IIC & $9(15.3 \%)$ & $10(10.8 \%)$ & $19(12.6 \%)$ \\
\hline Stage III & $0(0.0 \%)$ & $12(12.9 \%)$ & $12(7.9 \%)$ \\
\hline Stage IV & $12(20.7 \%)$ & $26(28.0 \%)$ & $38(25.2 \%)$ \\
\hline Total & $58(100.0 \%)$ & $93(100.0 \%)$ & $151(100.0 \%)$ \\
\hline \multicolumn{4}{|l|}{ Lymph node dissection } \\
\hline Yes, done & $18(31.0 \%)$ & 30 (32.3\%) & 48 (31.8\%) \\
\hline No, not done & $40(69.0 \%)$ & $63(67.7 \%)$ & $103(68.2 \%)$ \\
\hline Total & 58 (100.0\%) & 93 (100.0\%) & 151 (100.0\%) \\
\hline Total & 58 (38.4\%) & 93 (61.6\%) & 151 (100.0\%) \\
\hline
\end{tabular}


When staging the patients according to the TNM system, we found that every fourth patient with MM was in stage IV, respectively $20.7 \%$ of Group A and $28.0 \%$ of Group B (Table 2). Significantly higher is the proportion of Group B patients classified in stage 0 (8.6\% versus $1.7 \%$ in Group A) and stage IA $(18.1 \%$ versus $6.9 \%$ in Group A). With disease progression (stage IB - IIC), the proportion of patients with SLNB increases $(\chi 2=27.287, d f=7, p=0.001)$. There is no correlation between the studied variables $(p=$ 0.567).

\subsection{Mortality and survival}

Of all 151 patients in the study, 46 died, representing 30.5 per 100 patients with malignant melanoma. Mortality rate is higher in patients without SLNB (32.3\% versus $27.6 \%$ in Group A). However, the differences in the two groups are not statistically significant $(p=0.544)$.

Median survival (expressed in months) in patients with malignant melanoma (MM) is 72 months, $\mathrm{SE}=$ 20.704 at $S(t)=0.5$. The median survival $(\bar{x})$ in patients with MM and SLNB performed is 59.1 months $(\mathrm{SE}=3.2, \mathrm{Cl}=52.7 \div 65.4)$ and is lower than in patients with the same diagnosis but without $\mathrm{SLNB}(\overline{\mathrm{x}}=$ 68.8 months, $\mathrm{SE}=11.5$ months, $\mathrm{Cl}=46.2 \div 91.5$ ). However, the log rank test does not confirm these differences to be significant $(\log$ rank $=1.372, d f=1, p=0.241)$.

The likelihood of a patient with MM without SLNB to survive 7 months is $97.8 \%$, and in patients with melanoma and performed SLNB - 98.3\%. The 14 -months probability is $91.2 \%$ for Group B and $94.7 \%$ for Group A. The survival curve for patients in Group B has a steep downward trend which shows a worse prognosis in the first months after diagnosis, compared to Group A (Figure 2).

\section{Discussion}

For a sentinel lymph node biopsy to be performed, the sentinel node must be stained with a lymphotropic agent which makes it easier to detect. It is a molecule weighing more than $5000 \mathrm{D}$, which is injected intradermally and reaches predilectionally the lymphatic system. Patent blue $\mathrm{V}$ and radioactive Technetium 99Th Sulfur Colloid are used as tracers [12,13].

The main advantages of sentinel lymph node biopsy in cutaneous malignant melanoma, according to the most recent trials (MSLT 1 and 2) are:

- The result is a powerful prognostic factor;

- Complete lymph node dissection after detection of positive sentinel lymph node in some patients with thin malignant melanomas, all medium-thick malignant melanomas and thick malignant melanomas, improves their survival in good health;

- Complete lymph node dissection after detection of positive sentinel lymph node in some patients with thin malignant melanomas, and in all medium-thick malignant melanomas, improves their survival in good health and overall survival; 
- The result is the basis for implementation of effective postoperative therapy;

- It is a very sparing operative procedure $[14,15]$

There is a direct correlation between the thickness of cutaneous malignant melanoma and the percentage of sentinel lymph nodes affected by the metastatic process, which is shown in Table 3 .

Table 3. Percentage of positive SLNBs by thickness of malignant melanoma

\begin{tabular}{|c|c|}
\hline Breslow Thickness $(\mathrm{mm})$ & Positive sentinel lymph nodes \\
\hline$\leq 1$ & $\leq 5 \%$ \\
\hline $1-4$ & $15-20 \%$ \\
\hline$>4$ & $>40 \%$ \\
\hline
\end{tabular}

A comprehensive analysis of data regarding patients' distribution by sex shows a slight prevalence of males $78(51.7 \%)$. The differences are minimal and nonsignificant, however, still presenting a higher risk of developing malignant melanoma in men. This trend is reflected in other similar, large-scale surveys conducted in Australia and New Zealand [16,17].

The sex distribution of our patients in the two groups shows prevalence of women in the SLN biopsy group - 32 (55.2\%), whereas men are predominant in the non-SLN group 52 (55.9\%). The results of a multicenter study with 612 patients by Gershenwald et al. [18] are opposite to ours and demonstrate a predominance of men $(57.5 \%)$ in the SLN biopsy group. The data is not straightforward and the differences are not significant. This suggests that no significant causal link can be drawn.

The median age of 65.0 years in our patients with cutaneous malignant melanoma is higher than that reported by Ali et al. [19] - 57.0 years, in a worldwide study of the epidemiology of malignant melanoma. The majority of our patients are older, which should not reassure us because our youngest patient is only 17 years old. This a particular concern meaning that the disease is affecting much younger people.

The differences between the median age of our patients in the two study groups are not significant, which correlates with the results of a multicenter study by Gutzmer et al. [20] involving 673 patients.

The significantly higher percentage of patients with achromatic melanoma in the non-SLN biopsy group $(12.9 \%$ to $3.4 \%)$ is due to the fact that this histologic variant of cutaneous melanoma is diagnosed on a later clinical stage because of its atypical clinical manifestation, which in most cases does not allow for SLN biopsy [21]. 
We report a lower mean Breslow tumor thickness of $1.8 \mathrm{~mm}$ (Mdn, $1 \div 5 \mathrm{Min}$, Max) in the SLN biopsy group, compared to an average thickness of $2.5 \mathrm{~mm}$ (Mdn, $0 \div 11 \mathrm{Min}$, Max) in the group without SLN biopsy. Additionally, we observe a significantly lower percentage of patients with a melanoma thickness greater than $4.1 \mathrm{~mm}-13.2 \%$ in the same group, compared to $32.2 \%$ for the other one. This indicates that we have met precisely one of the main indications for performing SLNB, namely, Breslow thickness of malignant melanoma to be between 0.75 and $4.1 \mathrm{~mm}$. [22,23,24,25].

Statistical data analysis of performed lymph node dissection in the two groups studied by us shows that their frequency is very close, and is getting on for $31-32 \%$. This is $10 \%$ higher than the data of $20.8 \%$ reported by Morton et al. [26] in the final results of the largest MSLT I study to date, and indicates that the majority of our patients are in advanced stage of the disease when melanomas have already spread to lymphatic metastases. This is a very negative trend shown in our study, in all likelihood related to the late diagnosis of the disease.

Comparing our data regarding MM stage for SLNB group to those in the non-SLNB group, we observe that the percentage of patients in the first two and the last two stages of the disease is significantly higher in the non-SLNB group. This shows once again that we have strictly adhered to the rule that SLN biopsy is not recommended for patients with tumor thickness $<0.75 \mathrm{~mm}$, and stage 0 and IA, respectively, as the risk of lymphatic metastases is below $5 \%$. Same refers for the cases with tumor thickness $>4.1 \mathrm{~mm}$, since the risk of lymphatic metastases is greater than $40 \%$ and the benefit of SLN biopsy is unclear $[22,23,24,25]$.

Statistical analysis of mortality in the groups with and without SLN biopsy shows slightly lower rates for the first one (27.6\% to $32.3 \%)$, the differences are not significant. We did not find any significant differences between the groups in the survival rate. This matches the conclusion of Sladen et al. made upon summarizing data from the largest MSLT I study so far, that there is no significant difference in survival and mortality of patients from the two groups [27].

\section{Conclusions}

Patients with achromatic melanoma have significantly fewer SLN biopsies performed because of a late diagnosis.

Most of our patients are diagnosed at a later stage when lymphatic metastases are already present which leads to a significant increase in lymph node dissections performed.

There is no significant difference in mortality and survival in the SLNB and non-SLNB groups.

\section{List Of Abbreviations}

SLNB - sentinel lymph node biopsy 
SLN - sentinel lymph node

MM - malignant melanoma

TNM - tumor staging system

MSLT - abbreviation of study

\section{Declarations}

\section{Ethics approval and consent to participate}

The study was approved by the Ethics Committee of the Medical University of Pleven, Bulgaria through document number 454-КЕНИД / 21.06.2017.

The research was conducted in accordance with the updated Declaration of Helsinki and all patients, whose data are used for analysis, have signed an informed consent.

\section{Consent for publication}

All patients have signed an informed consent for publication of their data.

\section{Availability of data and materials}

The datasets used and/or analysed during the current study are available from the corresponding author on reasonable request.

\section{Declaration of authors competing interests}

The Authors declares that there is no competing interests.

\section{Funding statement}

This research received no specific grant from any funding agency in the public, commercial, or not-forprofit sectors.

\section{Authors' contributions}

Conceptualization - S.S.

Methodology - S.S. and A.K.

Software - A.Y., M.V. and Y.S.

Validation - S.S., A.Y. and A.K.

Formal Analysis - S.S., M.V. and Y.S. 
Investigation - S.S. and A.K.

Resources - S.S. and A.Y.

Data Curation - S.S., M.V. and Y.S.

Writing - Original Draft Preparation - S.S.

Writing - Review \& Editing - S.S., A.K. and A.Y.

Visualization - S.S., M.V. and Y.S.

Supervision - S.S. and Y.S.

Project Administration - S.S.

\section{Acknowledgements}

NA

\section{References}

1. Chin L, Merlino G, DePinho R. Malignant melanoma: modern black plague and genetic black box. Genes Dev 1998; 12: 3467-3481

2. Jhappan C, Noonan F, Merlino G. Ultraviolet radiation and cutaneous malignant melanoma. Oncogene 2003 May 19; 22(20):3099-112

3. Karimkhani C, Green A, Nijsten T, Weinstock M, Dellavalle R, Naghavi M, et al. The global burden of melanoma: results from the Global Burden of Disease Study 2015. Br J Dermatol.2017 Jul;177(1):134-140

4. Kozmin S, Slezak G, Reynaud-Angelin A, Elie C, de Rycke Y, Boiteux S et al. Ultraviolet A radiation is highly mutagenic in cells that are unable to repair 7,8-dihydro-8-oxoguanine in Saccharomyces cerevisiae. Proceedings of the National Academy of Sciences of the United States of America 2005; 102:13,538-43

5. Bishop J. Lentigos, Melanocytic Naevi and Melanoma In Rook's Textbook of Dermatology, 8th ed. Oxford, Blackwell publishing, 2010; 54.32-54.56

6. Loria D, Matos E. Risk factors for cutaneous melanoma: a case control study in Argentina. Int J Dermatol 2001; 40: 108-114

7. Hausauer A, Swetter S, Cockburn M, Clarke C. Increases in melanoma among adolescent girls and young women in California: trends by socioeconomic status and UV radiation exposure. Arch Dermatol. 2011; 147: 783-9

8. De Vries E, Bray F, Coebergh J, Parkin D. Changing epidemiology of malignant cutaneous melanoma in Europe 1953-1997: rising trends in incidence and mortality but recent stabilizations in western 
Europe and decreases in Scandinavia. International Journal of Cancer 2003; 107(1): 119-126

9. Levenback C, Intraoperative lymphatic mapping and sentinel node indentification: gynecologic applications, Resent Results cancer Res 2000; 157:150-8

10. Balch C, Gershenwald J, Soong S. Final Version of 2009 AJCC Melanoma Staging and Classification. J Clin Oncol 2009; 27(36): 6199- 6206

11. Sondak V, Zager J, Messina J, Thomas J. Sentinel lymph node biopsy as the standard of care for cutaneous melanoma. Clin Adv Hematol Oncol 2007; 5(6): 483-490

12. Baitchev G. Biopsy of the sentinel lymph nodes in malignant melanoma. My surgery.bg 28.09.2011

13. Morton D,Wen D, Wong J, Economou J, Cagle L, Storm F, et al. Technical details of Intraoperative lymphatic mapping for early stage melanoma. Arch Surg 1992; 127(4): 392-399

14. Morton D. On behalf of the MSLT Study Group Over view and update of the phase III Multicenter Selective Lymphadenectomy Trials (MSLT-I and MSLT-II) inmelanoma. Clin Exp Metastasis 2012; 29(7): 699-706

15. Spillane A, Read R, Thompson J. Sentinel node biopsy should be the standard of care for patients with intermediate and thick melanomas. Aust Fam Physician 2015; 44(8): 604-606

16. Australian Institute of Health and Welfare 2017. Australian Cancer Incidence and Mortality (ACIM) books: Melanoma of the skin. Canberra: AlHW. aihw.gov.au/acim-books

17. Clinical Practice Guidelines for the Management of Melanoma in Australia and New Zealand. 2008. [June 6, 2013]. nhmrc.gov.au/guidelines/publications/cp111

18. Gershenwald J, Thompson W, Mansfield P, Lee J, Colome M, Tseng C, et al. Multi-institutional melanoma lymphatic mapping experience: the prognostic value of sentinel lymph node status in 612 stage I or II melanoma patients. J Clin Oncol.1999 Mar; 17(3):976-83

19. Gutzmer R, Al Ghazal M, Geerlings H, Kapp A. Sentinel node biopsy in melanoma delays recurrence but does not change melanoma-related survival: a retrospective analysis of 673 patients. $\mathrm{Br} \mathrm{J}$ Dermatol.2005 Dec; 153(6):1137-41

20. Ali Z, Yousaf N, Larkin Melanoma epidemiology, biology and prognosis. EJC Suppl. 2013 Sep; 11(2): 81-91

21. Thomas N,Kricker A, Waxweiler W, Dillon P, Busman K, From L, et al. Comparison of Clinicopathologic Features and Survival of Histopathologically Amelanotic and Pigmented MelanomasA, PopulationBased Study. JAMA Dermatol. 2014;150(12):1306-1314

22. Ferrone C, Panageas K, Busam K, Brady M, Coit D. Multivariate prognostic model for patients with thick cutaneous melanoma: importance of sentinel lymph node status. Ann Surg Oncol 2002; 9(7): 637-645

23. Gajdos C, Griffith K, WongS, JohnsonT, ChangA, Cimmino V et al.Is there a benefit to sentinel lymph node biopsy in patients with T4 melanoma. Cancer 2009; 115(24): 5752-5760

24. Gershenwald J, Mansfield P, Lee J, Ross M. Role for lymphatic mapping and sentinel lymph node biopsy in patients with thick (> or = $4 \mathrm{~mm}$ ) primary melanoma. Ann Surg Oncol 2000; 7(2): 160-165 
25. Gutzmer R, Satzger I, Thoms K, Volker B, Mitteldorf C, Kapp A, et al. Sentinel lymph node status is the most important prognostic factor for thick (> or $=4 \mathrm{~mm}$ ) melanomas. J Dtsch Dermatol Ges 2008; 6(3): 198-203

26. Sladden M, Zagarella S, Popescu C, Bigby M. No survival benefit for patients with melanoma undergoing sentinel lymph node biopsy: critical appraisal of the Multicenter Selective Lymphadenectomy Trial-I final report. Br J Dermatol. 2015 Mar; 172(3):566-71

27. Morton D, Thompson J, Cochran A, Mozzillo N, Nieweg O, Roses D, et al. Final trial report of sentinelnode biopsy versus nodal observation in melanoma. N Engl J Med.2014 Feb; 370(7):599-609.

\section{Figures}
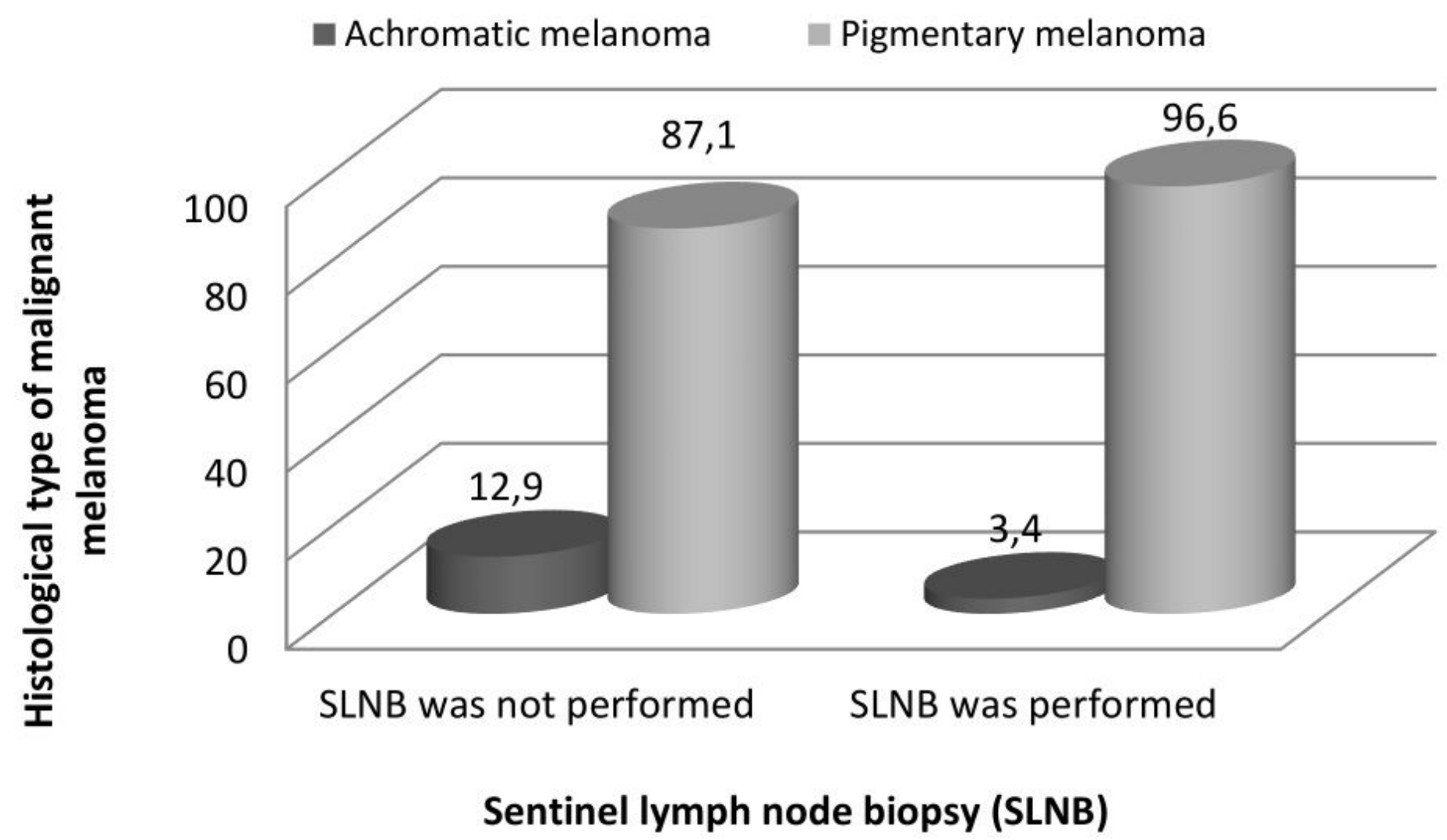

Figure 1

Distribution of patients with MM according to the performance of SLNB and histologic variant of tumor (\%) 


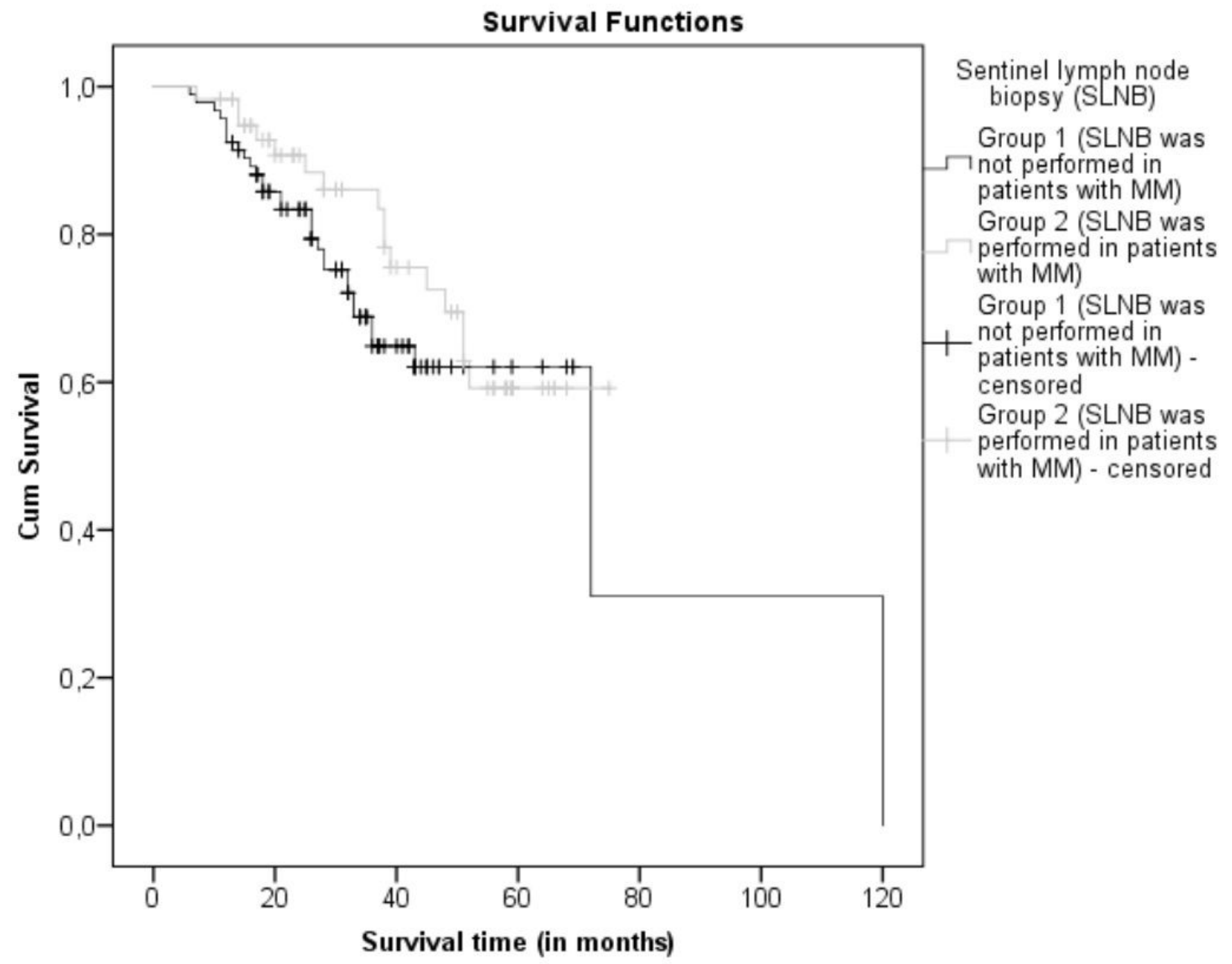

Figure 2

Kaplan-Meier Survival Curve for Patients with MM in Group A and Group B 